\title{
MODELQ DE MATURIDADE EM INTELIGENCIA ORGANIZACIONAL: uma visão integrada à gestão da informação, gestão do conhecimento e inteligência competitiva
}

\author{
ORGANIZATIONAL INTELLIGENCE MATURITY MODEL: \\ na integrated view of information management, \\ knowledge management and competitive intelligence
}

Lillian Maria Araújo de Rezende Alvares ${ }^{1}$
Anderson Luis Cambraia Itaborahy ${ }^{2}$
Renato Plácido Mathias Machado

\begin{abstract}
RESUMO
Apresenta a condição de dependência entre a gestão da informação, a gestão do conhecimento e a inteligência competitiva, a fim de demonstrar que informação e conhecimento organizacional estão associados de maneira indelével ao conceito de inteligência organizacional, mais especificamente a um modelo de maturidade em inteligência organizacional. A metodologia adotada foi a pesquisa exploratória qualitativa, baseada em revisão de literatura científica, a partir do rank criado pelo aplicativo de acesso livre Publish or Perish, que recupera e analisa citações acadêmicas, utilizando uma variedade de fontes científicas. Os resultados mostram que de fato a gestão da informação é o fundamento para a gestão do conhecimento, que por sua vez é a sustentação e dá seguimento às ações de inteligência competitiva. Conclui confirmando que a representação da maturidade como uma série de estágios lineares unidimensionais é também aplicada ao modelo expandido de inteligência organizacional.
\end{abstract}

Palavras-chave: Inteligência organizacional. Modelo de maturidade. Inteligência competitiva. Gestão do conhecimento. Gestão da informação.

\section{ABSTRACT}

Presents the condition of dependence between information management, knowledge management and competitive intelligence, to demonstrate that information and organizational knowledge is definitely associated with the concept of organizational intelligence. Specifically, with a maturity model of organizational intelligence. The methodology was the exploratory qualitative research, with literature review based on the ranking generated by the free access application Public or Perish, which retrieves and analyzes academic citations using a variety of scientific sources. The results show that information management is the foundation for knowledge management, which, in its turn, supports and enables competitive intelligence actions. It concludes by confirming that the representation of maturity as a series of one-dimensional linear stages is also applicable to the organizational intelligence expanded model.

Keywords: Organizational intelligence. Maturity model. Competitive intelligence. Knowledge management. Information management.

1 Professora da Faculdade de Ciência da Informação da Universidade de Brasília, Brasil. Coordenadora-Geral de Pesquisa e Manutenção de Produtos Consolidados. Instituto Brasileiro de Informação em Ciência e Tecnologia, Brasil. ORCID https://orcid.org/00000002-8920-0150. E-mail: lillianalvares@unb.br

2 Mestre em Gestão do Conhecimento e da Tecnologia da Informação pela Universidade Católica de Brasília, Brasil. Doutorando em Ciência da Informação pela Universidade de Brasília, Brasil. ORCID https://orcid.org/0000-0001-7164-1575. E-mail: anderson.itaborahy@gmail.com

3 Mestre em Gestão do Conhecimento e da Tecnologia da informação. Universidade Católica de Brasília, Brasil. ORCID https://orcid. org/0000-0002-9984-9260. E-mail: renatomachadodf@hotmail.com mail.com 


\section{INTRODUÇÃ̃}

0 termo inteligência organizacional aparece pela primeira vez nos estudos de Wilensky (1967), ao identificar os quatro problemas fundamentais e interdependentes das organizações: 0 estabelecimento de metas, componente essencial que orienta as atividades organizacionais e é sua própria razão de ser; a forma de garantir a conformidade com os padrões da organização; a maneira de assegurar as condições necessárias para o surgimento da inovação; e como lidar com o problema da coleta, processamento, interpretação e comunicação da informação técnica e política necessária aos processos de tomada de decisão, ao que ele chamou de Inteligência Organizacional (I0).

Em sua concepção, o conceito de inteligência organizacional enfatizou o reconhecimento do valor da informação, tanto proveniente do ambiente interno quanto externo à organização, os processos informacionais de agregação de valor e o processo de tomada de decisão. Com o tempo, ampliou-se, e se consolidou na década de 2000, como a "capacidade de uma corporação [...] reunir a informação, inovar, criar conhecimento e atuar efetivamente baseada no conhecimento que ela gerou" (CERVANTES et al., 2010, p.51). Com efeito, esse conceito remete ao entendimento de que a inteligência organizacional

[...] constitui uma capacidade organizacional, desenvolvida por meio de aprendizado sistemático, que permite à organização perceber adequadamente seu ambiente externo e interno por meio do processamento e uso de informações e da geração de novos conhecimentos organizacionais que contribuem para a tomada de decisões eficaz para a solução de problemas e orientação estratégica em ambientes em constante mudançăa . (CRUZ; DOMÍNGUEZ, 2007, s/p. tradução nossa).

Para Tarapanoff, Valentim e Alvares (2016), inteligência organizacional é um modelo de gestão que inclui os seguintes elementos e aspectos do ambiente organizacional: cultura, comunicação e aprendizagem organizacional, que por sua vez são tratados também no escopo da gestão da informação e a gestão do conhecimento. Sendo assim, na definição das autoras, inteligência organizacional pode ser entendida como um modelo integrado de gestão da informação e da gestão do conhecimento, conforme a Figura 1.

$4 \quad$ Nas palavras dos autores: constituye una capacidad organizacional, desarrollada por medio del aprendizaje sistemático, que permite a la organización percibir adecuadamente su ambiente externo e interno por medio del uso y procesamiento de la información proveniente de estos, y generar nuevos conocimientos organizacionales que contribuyan a una efectiva toma de decisiones para la resolución de problemas y la orientación estratégica ante ambientes cada vez más cambiantes. 
Figura 1 - Modelo integrado de inteligência organizacional
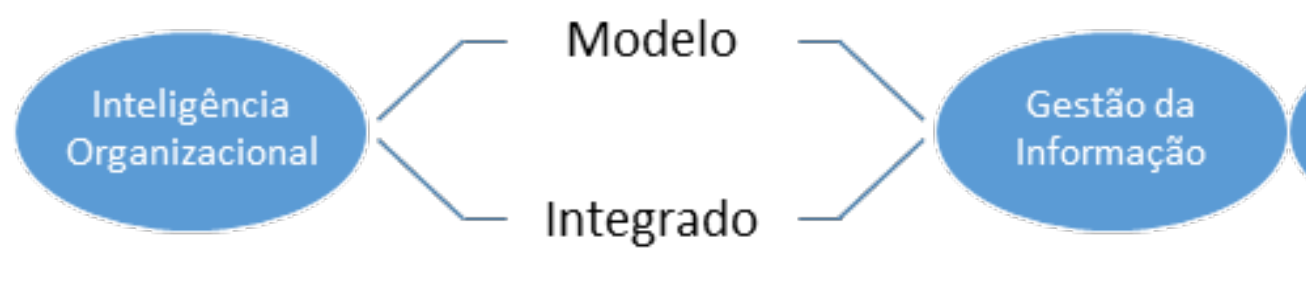

Fonte: Elaborado pelos autores, baseado em Tarapanoff, Valentim e Alvares (2016)

Soma-se a este modelo integrado, a necessidade do entendimento harmonizado com os demais conceitos de inteligência, uma vez que na terminologia acerca de termos e conceitos adjacentes à expressão inteligência organizacional existem polissemias que precisam ser reconhecidas ${ }^{5,6}$. HaberVeja e Más-Basnuevo (2013), Núñez Paula (2002) e Orozco (1998) afirmam ser a 10 o termo mais genérico da capacidade de inteligência no contexto organizacional, como mostra a Figura 2.

Figura 2 - Representação da percepção dos termos adjacentes à inteligência organizacional

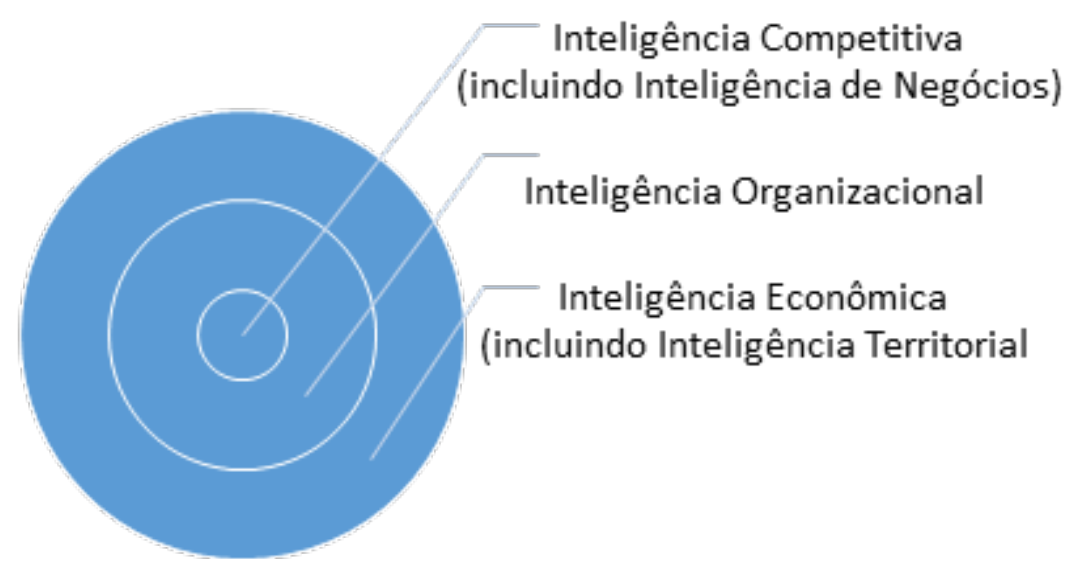

Fonte: Elaborado pelos autores

Os termos adjacentes à inteligência organizacional também foram apresentados por Tarapanoff, Valentim e Alvares (2016). As autoras definem inteligência de negócios como o "uso de tecnologias de

5 Para fins dessa pesquisa, apenas os termos inteligência de negócios, inteligência competitiva e inteligência econômica serão apresentadas brevemente, apenas com o objetivo de auxiliar na definição de inteligência organizacional

6 Para conhecer mais sobre terminologias e definições de inteligência, veja o artigo TARAPANOFF, K. ; VALENTIM, M. L. P. ; ALVARES, L. Trajetórias terminológicas relacionadas com a inteligência competitiva. In: INVESTIGACIÓN EN INFORMACIÓN, DOCUMENTACIÓN Y SOCIEDAD: PERSPECTIVAS Y TENDÊNCIAS. Vol. 2. Madrid, 8, 2016. Anais [...]. Madrid, Espanha: Universidad Complutense de Madrid/Facultad de Ciencias de la Documentación/ Departamento de Biblioteconomía y Documentación, 2016. p. 449-467. 
integração e análise de dados internos e externos à organização a partir de fontes de origens diversas, com objetivo de disponibilizar informação para tomada de decisão." (p. 462). As autoras reservam para o termo inteligência competitiva "o processo contínuo de coleta, análise e gerenciamento de dados, informações e conhecimento sobre o ambiente de negócios em que a organização está inserida, visando obter vantagem competitiva" (p. 456). As práticas de inteligência de negócios, pode-se afirmar, estão integralmente contidas nas práticas de inteligência competitiva.

E inteligência econômica como "um modelo de governança, cujo objeto se refere a informação estratégica que tem como finalidade a competitividade e a segurança da economia e das empresas nacionais", definido por Henri Dou (p. 458), conceito esse que inclui a inteligência territorial, "a aplicação da inteligência econômica utilizada como meio de desenvolvimento regional sustentável, em especial das pequenas empresas, focada em suas cadeias de valor, baseada na cooperação e em parcerias público-privadas" (p. 459).

A partir do entendimento acima pode-se afirmar que a inteligência organizacional depende também das ações da inteligência competitiva e para compreender a área na sua plenitude, ao modelo integrado precisamos somar as ações de inteligência. Conclui-se, por conseguinte, que o modelo expandido de inteligência organizacional inclui também a inteligência competitiva, além da gestão da informação, da gestão do conhecimento, conforme a Figura 3 a seguir.

Figura 3 - Modelo expandido de Inteligência Organizacional

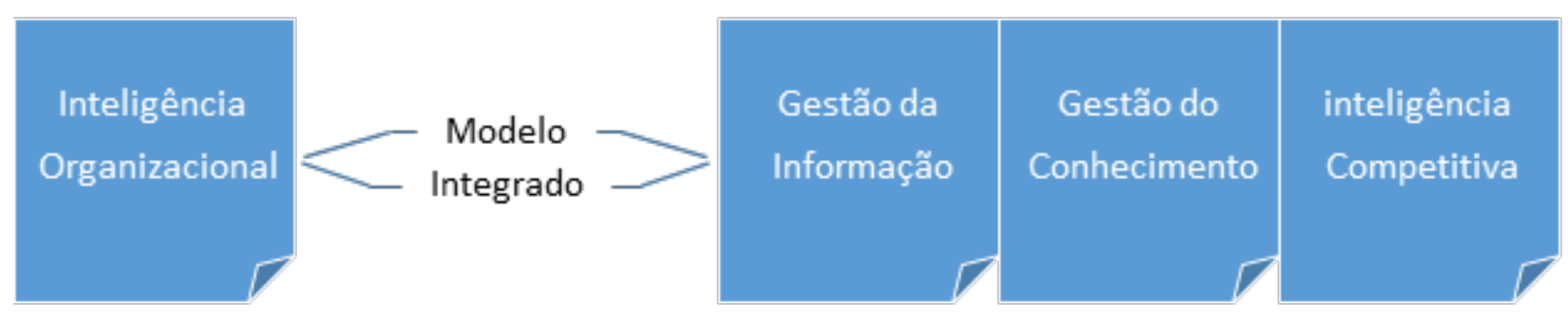

Fonte: Elaborado pelos autores

No cenário apresentado, o problema que a pesquisa está investigando é a condição de dependência entre a gestão da informação, a gestão do conhecimento e a inteligência competitiva, a fim de demonstrar que existe mais do que uma estreita relação entre elas, que existe de fato uma dependência de maturidade entre estes componentes constituintes do modelo expandido de inteligência organizacional, que se inicia no estágio inicial da gestão da informação, que por sua vez é o fundamento 
para a gestão do conhecimento, que por sua vez é a sustentação e dá seguimento às ações de inteligência competitiva.

Em outras palavras, busca demonstrar que a gestão da informação fornece uma base estável para os esforços de gestão do conhecimento, uma vez que utiliza abordagens e práticas semelhantes e se vale das mesmas interfaces disciplinares para se desenvolver. Logo, se a organização não consegue implementar a gestão da informação é provável que não consiga prosseguir para o escopo mais amplo necessário à gestão do conhecimento. Da mesma maneira, a pesquisa pretende demonstrar que existe mais do que uma sinergia entre gestão do conhecimento e inteligência competitiva, de fato, pode-se esperar da gestão do conhecimento ser condição essencial à inteligência competitiva.

Para evidenciar esses argumentos a pesquisa tem como objetivo apresentar um modelo de maturidade em inteligência organizacional, a partir dos resultados alcançados em três segmentos de pesquisa apresentados de maneira independentes: o primeiro segmento apresenta o que são modelos de maturidade, a gestão da informação e os modelos de maturidade em gestão da informação, em um artigo intitulado "Modelo de maturidade em gestão da informação: uma visão diacrônica". 0 segundo segmento apresenta a gestão do conhecimento, os modelos de maturidade em gestão do conhecimento e sua relação com os modelos de maturidade em gestão da informação, em um artigo intitulado "Modelo de maturidade em gestão do conhecimento: uma visão diacrônica". Esta comunicação é o terceiro e último segmento, intitulado "Modelo de maturidade em inteligência organizacional: uma visão integrada à gestão da informação, gestão do conhecimento e inteligência competitiva”, ocasião que a pesquisa apresenta a inteligência competitiva, os modelos de maturidade em inteligência competitiva, sua relação com a gestão do conhecimento (e a relação da gestão da informação com a gestão do conhecimento) e o modelo de maturidade em inteligência organizacional.

\section{METODOLOGIA}

A metodologia adotada foi a pesquisa exploratória qualitativa, baseada em revisão de literatura científica. A fonte da revisão de literatura foram as mais de cinquenta referências bibliográficas selecionadas na disciplina "Estudos avançados em ciência da informação: modelos de maturidade em gestão do conhecimento"7 do Programa de Pós-graduação em Ciência da Informação da Universidade de Brasília, cuja ementa informa que o curso é destinado ao aprimoramento da investigação nos

$7 \quad$ Disponível em < http://lillianalvares.fci.unb.br/estudos-avancados $>$ 
modelos de maturidade internacionais em gestão da informação, gestão do conhecimento e inteligência competitiva, identificados a partir de 1993 e cujos objetivos são realizar estudos avançados a partir de literatura de referência da área e em discussão em sala de aula, com apresentação de conceito, histórico e fundamentação teórica sobre modelos de maturidade em gestão, em sistemas de informação e em desenvolvimento de software (Capability Maturity Model CMM e CMMi), áreas que mais progrediram na definição e aplicação de modelos de maturidade, e analisar a aplicação dos modelos e criar um referencial teórico de modelo de maturidade em inteligência organizacional.

Além das referências da disciplina, cada um dos três segmentos da pesquisa elegeu artigos específicos baseado no rank criado pelo aplicativo de acesso livre Publish or Perish, que recupera e analisa citações acadêmicas, utilizando uma variedade de fontes científicas (incluindo Google Scholar e Microsoft Academic Search) para obter as referências. 0 aplicativo analisa e apresenta as seguintes métricas, suficientes para a escolha dos mais indicados: número total de artigos recuperados, número total de citações por artigo, média de citações por artigo, citações por autor, artigos por autor e citações por ano, análise do número de autores por artigo, entre outros. Estas referências foram a base para criação dos argumentos utilizados para a elaboração de um modelo de maturidade em inteligência organizacional.

Dentre os resultados alcançados por esta pesquisa, está principalmente o esclarecimento do escopo de atuação e das relações existentes entre a gestão da informação, gestão do conhecimento e inteligência competitiva, que eventualmente podem ser objeto de divergência. Além disso, demonstrou que existe uma escala de evolução entre elas, tendo início com os esforços de gestão da informação, que será a fundação para a próxima etapa da gestão do conhecimento, que por sua vez alicerça as ações de inteligência competitiva. Ao demonstrar essa relação de dependência, a pesquisa apontou que essas três frentes juntas e em evolução, conformam um modelo integrado de maturidade em inteligência organizacional.

\section{REVISÃO DE LITERATURA}

\subsection{Modelos de maturidade em gestão da informação e gestão do conhecimento}

0 processo de mudança nas organizações tem sido objeto de pesquisa permanente nas ciências da administração. Para entender como as organizações mudam, são necessários conceitos, metáforas e teorias de outras disciplinas, variando do desenvolvimento infantil à biologia evolutiva 
(VAN DE VEN; POOLE, 1995)․ A Teoria do Ciclo de Vida é uma metáfora de crescimento para explicar o desenvolvimento em uma organização, frequentemente usada como referência ao ciclo de vida de organizações, produtos e empreendimentos, bem como estágios no desenvolvimento de carreiras, grupos e unidades organizacionais. Nesta teoria, a mudança é iminente, regulada por uma lógica que regula o processo de mudança e move a entidade a partir de um determinado ponto de partida em direção a um fim subsequente. A forma latente torna-se progressivamente mais realizada, madura e diferenciada. Segundo Van de Ven e Poole (1995):

A progressão típica de eventos de mudança em um modelo de ciclo de vida é uma sequência unitária (segue uma única sequência de estágios ou fases), que é cumulativa (características adquiridas em estágios anteriores são retidas em estágios posteriores) e conjuntivos (os estágios estão relacionados de tal modo que derivam de um processo subjacente comum). Existe essa progressão porque a trajetória até 0 estado final é pré-configurada e requer uma sequência histórica de eventos. Cada um desses eventos contribui com uma peça para 0 produto final e devem ocorrer em uma ordem prescrita, porque cada peça prepara o palco para o próximo. Cada estágio do desenvolvimento é visto como um precursor necessário das etapas seguintes ${ }^{9}$. (VEM; POOLE, 1995, p. 515)

Os modelos de maturidade estão no contexto da mudança por ciclo de vida, orientados a uma habilidade específica, conduzindo este processo evolutivo a partir da formalização das atividades desejadas para a próxima etapa. Todos os modelos definem várias dimensões em vários estágios de maturidade, formando uma matriz de desempenho que caracteriza cada divisão estabelecida. Os componentes esperados dos modelos de maturidade, grosso modo, são: (i) a definição de vários níveis (geralmente de três a seis), (ii) dimensões em que se sustenta o modelo, (iii) categorias de cada dimensão e (iv) breve descrição da característica fundamental de cada divisão ${ }^{10}$.

Modelos de maturidade estão sendo cada vez mais utilizados no campo da informação, tanto em uma abordagem para melhoria contínua, quanto para comparação ou autoavaliação. Machado, Itaborahy e Alvares (2020) avaliaram os seguintes modelos de gestão da informação: Gartner Enterprise

8 Os autores estudaram várias teorias de mudança organizacional, que poderiam ser agrupadas em quatro escolas básicas de pensamento: ciclo de vida, teleologia, dialética e evolução. Um modelo de ciclo de vida descreve o processo de mudança em uma entidade como progresso por meio de uma sequência necessária de etapas. Um modelo teleológico vê o desenvolvimento como um ciclo de formulação de objetivos, implementação, avaliação e modificação de metas com base em o que foi aprendido pela entidade. Nos modelos dialéticos de desenvolvimento, surgem conflitos entre entidades que defendem tese e antítese opostas que colidem para produzir uma síntese, que com o tempo se torna a tese para o próximo ciclo de uma progressão dialética. E um modelo evolutivo de desenvolvimento consiste em uma sequência repetitiva eventos de variação, seleção e retenção, sobretudo baseado na competição por recursos escassos entre entidades que habitam uma população.

$9 \quad$ Nas palavras dos autores: The typical progression of change events in a life-cycle model is a unitary sequence (it follows a single sequence of stages or phases), which is cumulative (characteristics acquired in earlier stages are retained in later stages) and conjunctive (the stages are related such that they derive from a common underlying process). There is such a progression because the trajectory to the final end state is prefigured and requires a specific historical sequence of events. Each of these events contributes a piece to the final product, and they must occur in a prescribed order, because each piece sets the stage for the next. Each stage of development is seen as a necessary precursor of succeeding stages.

10 A primeira e a segunda parte desta pesquisa ("Modelo de maturidade em gestão da informação: uma visão diacrônica" e "Modelo de maturidade em gestão do conhecimento: uma visão diacrônica") detalham com mais profundidade os modelos de maturidade. 
Information Management Maturity Model (EIMM, 2008), ARMA Information Governance Maturity Model (IGMM, 2010), Enterprise Content Management Maturity Model (ECM3, 2010), Asset Management Maturity Model (AMMM, 2011), Digital Asset Management Maturity Model (DAMM, 2017) e E-ARK Information Governance Maturity Model (A2MIG0, 2017) e concluíram, após avaliação quantitativa dos MMGI, baseada em atributos de robustez do modelo, que o modelo ECM3 "atende plenamente 0 processo preconizado por Choo (1995) para gestão da informação, cujas sete etapas estavam presentes nas dimensões, categorias e atributos dos cinco níveis de maturidade do modelo". Cabe destacar que o modelo A2MIG0, de fato, recebeu maior pontuação na pesquisa, mas é, no entanto, um modelo de governança da informação, que atua nos níveis especializados de preservação digital.

Os mesmos autores, em Itaborahy, Machado, e Alvares (2020), também avaliaram os seguintes modelos de maturidade em gestão do conhecimento: Knowledge Management Maturity Model (KM3 Gallagher e Hazlett, 2000), Knowledge Management Maturity Model (KMMM Siemens, 2002), Enabling People and Innovation through Knowledge (EPIK Intel, 2003), Organizational Knowledge Assessment (OKA World Bank, 2008), Asian Productivity Organization Knowledge Management (APO KM, 2009) e General Knowledge Management Maturity Model (G-KMMM Pee e Kankanhali, 2009) e decidiram por apresentar proposta, designada pela sigla MMGC (Modelo de Maturidade em Gestão do Conhecimento) que satisfaz às condições da norma ISO 30401 Sistema de Gestão do Conhecimento (ISO, 2018) e contempla as dimensões de maturidade da gestão da informação, conforme proposto por Machado, Itaborahy e Alvares (2020).

\subsection{Inteligência competitiva e os modelos de maturidade em inteligência competitiva}

Existem numerosas definições de Inteligência Competitiva na literatura, muito imprecisas e frequentemente usada por outros conceitos relacionados, conforme apresentado no início deste artigo. Para Kahaner (1997), um dos fundadores da Sociedade de Profissionais de Inteligência Competitiva (SCIP), "Inteligência competitiva é um programa sistemático para coletar e analisar informações sobre as atividades de seus concorrentes e tendências gerais de negócios para promover os objetivos de sua própria empresa ${ }^{11}$ (p. 16)"

Mais do que uma definição, conhecer os elementos constituintes do processo de inteligência competitiva é essencial para a compreensão do seu escopo de atuação, que frequentemente é citado na

11 No original: Competitive intelligence is systematic program for gathering and analyzing information about your competitors' activities and general business trends to further your own company's goals 
literatura como um processo de cinco fases (de atividades formais e informais): planejamento e foco (que incluem a identificação dos usuários e suas necessidades), coleta de dados, informações e conhecimento (por monitoramento do ambiente de negócios e que inclui a representação, organização e o armazenamento de informações - etapa crucial, dependente de um eficiente gerenciamento de informações), análise, disseminação (para os tomadores de decisão e estrategistas) e ação (KAHANER, 1998).

Isso é, a inteligência competitiva é o processo de identificação e coleta de informações relevantes, de várias fontes (internas e sobretudo externas) e analisadas para atender às possíveis estratégias organizacionais. Para ser eficaz, um sistema de inteligência competitiva deve produzir um fluxo constante de informações precisas e atuais, que devem chegar aos tomadores de decisão da empresa.

A fase final do processo de inteligência consiste na comunicação eficaz da análise e aqui é fundamental compreender como os tomadores de decisão desejam receber as informações. Elas podem variar de relatórios completos e formais até breves descrições dos fatos essenciais, sempre com uso extensivo de gráficos e imagens. De fato, o resultado mais esperado da inteligência competitiva é a capacidade de criar perfis informativos que ajudam a organização na tomada de decisão.

Percorrer esse caminho e garantir as condições para sua realização por meio da avaliação de maturidade aumenta a chance de sucesso em programas e ações de inteligência competitiva. Oubrich et al (2018) afirmam que Heppes e Du Toit (2009) desenvolveram o único modelo de maturidade do IC conhecido com seis dimensões avaliadas em três níveis de maturidade. Baseado naquele modelo e em resultados da pesquisa, os autores propuseram um modelo de maturidade em IC baseado em três níveis de maturidade e nas seguintes dimensões: (i) estratégia e cultura, (ii) relação com a gestão, (iii) estrutura, (iv) recursos, (v) sistema (vi) usuários e aplicação, (vii) artefatos e capacidades, (viii) produtos analíticos e (ix) impacto.

\section{RESULTADOS}

\subsection{Relação de dependência entre gestão da informação e gestão do conhecimento}

0 relacionamento entre gestão da informação e gestão do conhecimento é objeto de estudo sobre ambientes organizacionais desde pelo menos 1970, quando o governo americano escolheu 0 tema "The management of information and knowledge" para o painel de ciência e tecnologia daquele 
ano ${ }^{12}$. Bundy (1970) na ocasião afirmou que a combinação da gestão da informação e do conhecimento é uma capacidade e um benefício potencial, que devem ser explorados, considerando que a quantidade de informação necessária e cada vez mais disponível, sobrecarrega os sistemas de conhecimento. Em outras palavras, os fluxos de informações necessárias e não gerenciadas que inundam as organizações necessitam de complemento para saciar a "sede de compreensão". Nas palavras do autor :

No entanto, se fluxos de informações não assimiladas e certamente não gerenciadas nos inundam em meio a esse tipo de sede de compreensão, o sistema de informações computacionais, tomado de forma abrangente, parece oferecer uma capacidade sem precedentes ... de converter dados em conhecimento ${ }^{13}$. (p. 4)

Van de Hoven (2006) afirma que o gerenciamento de recursos de informação fornece uma base estável para esforços de gestão do conhecimento, já que a informação compartilhada é uma das premissas da gestão do conhecimento, isso é, a eficiente gestão da informação é vista como prérequisito essencial para as estratégias de gestão do conhecimento. 0 autor ainda afirma que tanto uma como a outra tem objetivos semelhantes, utiliza abordagens semelhantes, tem práticas e disciplinas constituintes comuns e portanto, se uma organização não consegue implementar a gestão da informação é improvável que consiga lidar com o escopo mais amplo necessário à gestão do conhecimento.

À propósito, Davenport e Marchand (2001) argumentam que existe um grande componente do gerenciamento de informações na gestão do conhecimento, e que muito do que se entende de gestão do conhecimento, é de fato, gestão da informação. Para evitar qualquer dúvida em relação ao espaço de atuação de cada uma, cabe destacar a colocação de Schlögl (2005, p.9) para evitar o conflito: [...] gestão do conhecimento significa a gestão das práticas de trabalho que visam melhorar a geração de novos conhecimentos e o compartilhamento de conhecimentos existentes ${ }^{14}$.

A pesquisa de Chen, Snyman e Sewdass (2005) mostra claramente a relação entre gestão de documento, gestão de informações e gestão do conhecimento ${ }^{15}$. Os autores afirmam que a gestão do conhecimento (GC) pode ser entendida como a soma da gestão de informação e da gestão de

12 BUNDY, M. Keynote speaker. In: PANEL ON SCIENCE AND TECHNOLOGY: THE MANGEMENT OF INFORMATION AND KNOWLEDGE, 11, 1970, Washington. Proceedings [...]. Washington: Committee on Science and Astronautics, U.S. House of Representatives, 1970.

13 Nas palavras do autor: Yet, if streams of unassimilated, and certainly unmanaged, information inundate us in the midst of this kind of thirst for understanding, computer information system, taken comprehensively, do seem to offer an unprecedent capability ...to convert data into knowledge.

14 Nas palavras do autor: knowledge management means the management of those work practices that aim at improving the generation of new and the sharing of existing knowledge.

15 Esse artigo não vai tratar da relação entre gestão de documentos, embora esteja à continuidade desta pesquisa a investigação sobre modelos de maturidades em gestão de documentos. 
MODELO DE MATURIDADE EM INTELIGÊNCIA ORGANIZACIONAL:

uma visão integrada à gestão da informação, gestão do conhecimento e inteligência competitiva

pessoas (essa última com o propósito de alavancar a inteligência individual e coletiva ${ }^{16}$ ) já que inclui tanto o gerenciamento de informações (conhecimento explícito) quanto o gerenciamento de habilidades específicas dos indivíduos (pessoas com conhecimento tácito). A distinção entre conhecimento explícito e tácito ${ }^{17}$, por conseguinte, é fundamental para definir o escopo da gestão do conhecimento.

A pesquisa de Schlögl (2005) traz uma abordagem pertinente para organizar os espaços de atuação entre a gestão da informação e a gestão do conhecimento. Nessa perspectiva, ele inclui, além das divisões da gestão da informação orientada ao conteúdo e à tecnologia, a abordagem de capital intelectual, intimamente baseado no valor dos ativos intangíveis de uma organização. Segundo Corrall (1998), a escolha entre gestão do capital intelectual e gestão do conhecimento depende da ênfase dada à medição ou gerenciamento de ativos de conhecimento ${ }^{18}$.

16 Inteligência coletiva é a inteligência que emerge da comunicação e colaboração - formal e informal - de grupos de pessoas dentro e fora da empresa. Tecnologias web 2.0 permitem essa nova forma de trabalho colaborativo que está mudando a maneira como as pessoas trabalham, de compartilhar inteligência pessoal para criar e enriquecer a inteligência do grupo. (CASONATO, Regina. Knowledge management and enterprise information management are both disciplines for exploiting information assets. Stamford, Connecticut: Gartner, 2009)

17 Este trabalho não pretende apresentar os fundamentos da gestão do conhecimento, mas apenas para garantir o bom entendimento deste texto, pode-se brevemente expressar como conhecimento tácito, pela definição de Polanyi, é aquele que "não pode ser especificado em detalhes não pode ser transferido por prescrição... Pode ser passado apenas pelo exemplo do mestre para 0 aprendiz. Isso restringe 0 alcance da difusão ao dos contatos pessoais." 0 preceito básico de Polanyi é que, até certo ponto, todo 0 conhecimento inclui um grau de tácito, numa escala contínua do totalmente tácito para o totalmente explícito. É neste contexto que surge 0 conceito de conhecimento implícito, um conceito não discutido por Polanyi, mas importante para entender o continuum do conhecimento. A dimensão do conhecimento explícita e tácita é um dos tópicos mais discutidos na gestão do conhecimento a partir do trabalho de Nonaka e Takeuchi (1995), que apresentam uma nova descrição do conhecimento em um contexto organizacional. Eles tomaram o trabalho de Polanyi sobre 0 conhecimento pessoal e 0 estenderam ao conhecimento organizacional. (POLANYI, Michael. The tacit dimension. Chicago: University of Chicago Press, 2009.) (NONAKA, Ikujiro; TAKEUCHI, Hirotaka. The knowledge-creating company: How Japanese companies create the dynamics of innovation. Oxford: Oxford University Press, 1995.)

18 Os principais modelos de capital intelectual (Edvinsson e Malone, 1997; Kaplan e Norton, 1992; Stewart, 1997; e Sveiby, 1997) resultam da soma do capital humano (colaboradores e suas habilidades e experiências, etc) com 0 capital estrutural (patentes, negócios processos, cultura, experiência documentada, etc) com o capital de relacionamento (clientes, fornecedores, parcerias, reputação, marca, etc). Simplificando, capital intelectual = capital humano + capital estrutural + capital de relacionamento. 
Quadro 1 - Gestão da Informação e do Conhecimento: resumo dos principais objetos, termos e disciplinas relacionadas

\begin{tabular}{|c|c|c|c|c|}
\hline \multirow{2}{*}{ DISCIPLINAS } & \multirow{2}{*}{\multicolumn{2}{|c|}{$\begin{array}{l}\text { OBJETO } \\
\text { AMPLOS }\end{array}$}} & \multicolumn{2}{|c|}{ TERMOS } \\
\hline & & & RESTRITOS & \\
\hline \multirow{3}{*}{$\begin{array}{l}\text { Ciências da } \\
\text { Computação }\end{array}$} & \multirow{3}{*}{$\begin{array}{l}\text { Tecnologia da } \\
\text { Informação }\end{array}$} & Estrutura de dados & \multirow{3}{*}{$\begin{array}{l}\text { Gestão da } \\
\text { Informação Orientada } \\
\text { à Tecnologia }\end{array}$} & Gestão de Dados \\
\hline & & $\begin{array}{l}\text { Sistemas de } \\
\text { Informação }\end{array}$ & & $\begin{array}{l}\text { Gestão de } \\
\text { Sistemas de } \\
\text { Informacão }\end{array}$ \\
\hline & & $\begin{array}{l}\text { Infraestrutura de } \\
\text { informação }\end{array}$ & & $\begin{array}{l}\text { Gestão de } \\
\text { Infraestrutura de } \\
\text { informação }\end{array}$ \\
\hline \multirow{2}{*}{$\begin{array}{l}\text { Arquivologia, } \\
\text { Biblioteconomia } \\
\text { e Ciência da } \\
\text { Informação }\end{array}$} & \multirow[t]{2}{*}{$\begin{array}{l}\text { Informação } \\
\text { Codificada }\end{array}$} & Interna & \multirow[t]{2}{*}{$\begin{array}{l}\text { Gestão da } \\
\text { Informação Orientada } \\
\text { à conteúdos }\end{array}$} & \begin{tabular}{|l|} 
Gestão \\
Documental e \\
de Processos da \\
Informação \\
\end{tabular} \\
\hline & & Externa & & \begin{tabular}{|l|} 
Inteligência \\
Competitiva
\end{tabular} \\
\hline Administração & $\begin{array}{l}\text { Ativos do } \\
\text { Conhecimento }\end{array}$ & \begin{tabular}{|l} 
Criação e \\
Compartilhamento de \\
Conhecimento
\end{tabular} & $\begin{array}{l}\text { Gestão do } \\
\text { Conhecimento }\end{array}$ & $\begin{array}{l}\text { Gestão do Capital } \\
\text { Intelectual }\end{array}$ \\
\hline
\end{tabular}

Fonte: Adaptado de Schlögl (2005)

Considerando que as principais atribuições da gestão do conhecimento é facilitar sua criação e gerenciar a maneira como as pessoas compartilham e usam o conhecimento, Ponelis e Fairer-Wessels (1998) indicam que o gerenciamento de informações é visto como uma subdivisão do gerenciamento de conhecimento, pois entendem a criação de conhecimento como um processo de agregar valor às informações. Em consequência, afirmam que a ausência de programas e procedimentos adequados ao gerenciamento de informações levará à degradação e declínio da gestão do conhecimento. Para os autores, a gestão do conhecimento é uma dimensão adicional, que intensifica a necessidade de integração com a gestão da informação ${ }^{19}$.

\subsection{Relação de dependência entre gestão do conhecimento e inteligência competitiva}

Retomando as definições de gestão do conhecimento, cabe destacar os limites de abrangência espacial do conceito. Apesar de existirem mais de 100 definições, identificadas por Sutton (2008), este trabalho vai se concentrar naquelas que destacam que o gerenciamento de ativos de conhecimento está restrito ao ambiente interno da organização, que os esforços estão acontecendo para aprimorar o poder competitivo a partir dos ativos internos do conhecimento, voltado a explorar o potencial de 
conhecimento contido no capital humano (habilidades e competências) e no capital estrutural (bancos de dados, documentos, políticas, procedimentos e processos, entre outros).

Ou, segundo Ghannay e Mamlouk (2012) que resume esse entendimento, gestão do conhecimento é o processo pelo qual o desempenho organizacional é aprimorado por meio de um melhor gerenciamento do conhecimento corporativo. Seu objetivo é melhorar o gerenciamento dos processos internos de conhecimento para que todas as informações necessárias para as decisões corporativas possam ser disponibilizadas e usadas com eficiência. 0 mesmo autor, define a inteligência competitiva (IC) como um processo para reunir conhecimento útil sobre o ambiente de negócios externo e transformá-lo na inteligência necessária para decisões táticas ou estratégicas. Note que 0 foco desta definição é o ambiente externo, assim como a maioria das expressões da IC (MARCIAL, 2013). A combinação de GC e IC, portanto, fornece as condições necessárias ao tomador de decisão, que não pode prescindir de informações do ambiente interno e nem do ambiente externo.

Mesmo com o espaço de atuação claramente colocados, o objetivo de ambas é avaliar as decisões de negócios, localizar e entregar o conhecimento apropriado de dentro e de fora da organização. Segundo Hall e Bensoussan (1996), "têm objetivos semelhantes e são extensões naturais uma da outra". A diferença fundamental está no espaço de atuação, a gestão do conhecimento voltada ao que é próprio da organização e a inteligência competitiva voltada ao ambiente geral e específico.

A análise de Ghannay e Mamlouk (2012) mostra que a gestão do conhecimento, movida pelas forças internas, é o impulso necessário à inteligência competitiva, tendo em vista os elementos próprios de cada um, e considerando que são duas partes do mesmo todo, pois ambos são projetados para aplicar o conhecimento corporativo do ambiente interno e externo para obter vantagem competitiva a Iongo prazo. Sintetizando com as palavras de Calof (2008), sem o gerenciamento do conhecimento, não é possível criar inteligência competitiva, pois a inteligência competitiva requer acesso à informação.

\subsection{0 modelo de maturidade em inteligência organizacional}

A relação progressiva entre gestão da informação, gestão do conhecimento e inteligência competitiva é clara ao revelar que a informação estratégica organizacional deve ser tratada como um todo, compreendido como estágios de maturidade, que se sucedem pela capacidade obtida em cada dimensão a partir da formalização das atividades desejadas para a próxima etapa, conforme a Figura 4 a seguir. 
Figura 4 - Etapas Evolutivas da Informação Estratégica Organizacional

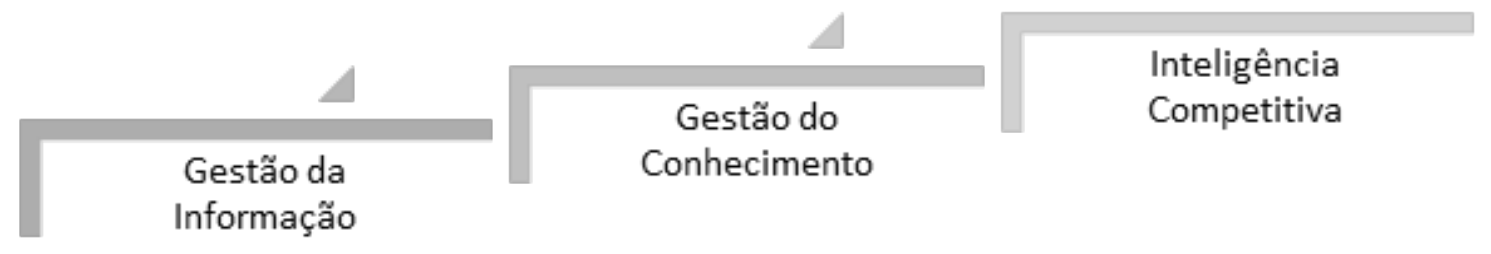

Fonte: Elaborado pelos autores

Esses elementos, per se, compõem o conceito de Inteligência Organizacional, apresentado por Tarapanoff, Valentim e Alvares (2016) e expandido nesta pesquisa, levando, ato contínuo, a proposição de um modelo de maturidade em inteligência organizacional. Assim, considerando a visão diacrônica da gestão da informação, da gestão do conhecimento e da inteligência competitiva identificadas para este trabalho e considerando as relações de dependência existentes entre as três etapas, essa pesquisa propõe a seguinte representação da maturidade, orientados a uma aplicação prática de uso prescritivo, no processo evolutivo da informação estratégica organizacional, por meio de uma série de estágios lineares unidimensionais. 
MODELO DE MATURIDADE EM INTELIGÊNCIA ORGANIZACIONAL:

uma visão integrada à gestão da informação, gestão do conhecimento e inteligência competitiva

\begin{tabular}{|c|c|c|c|c|c|c|}
\hline \multirow{2}{*}{\multicolumn{2}{|c|}{ 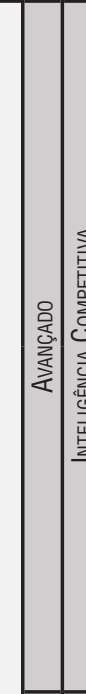 }} & 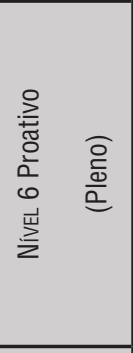 & 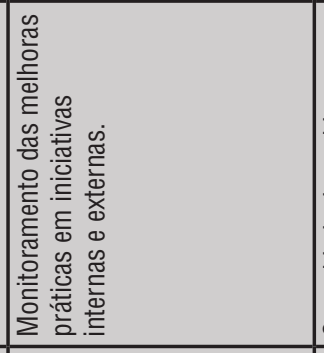 & 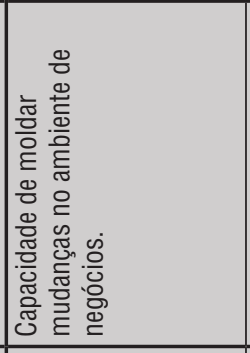 & 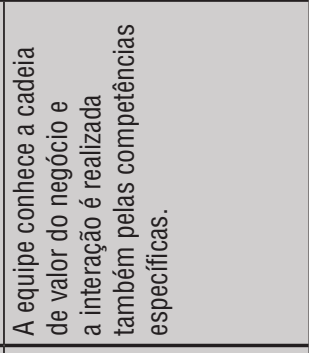 & 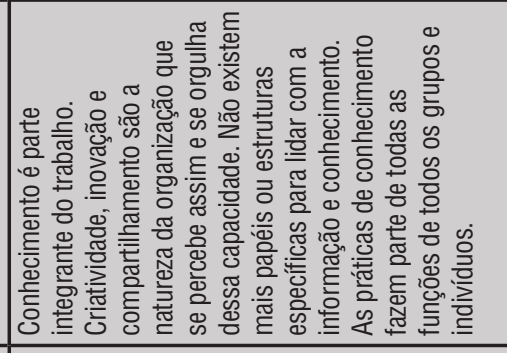 \\
\hline & & 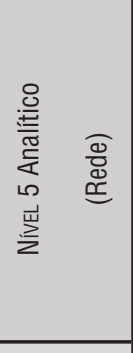 & 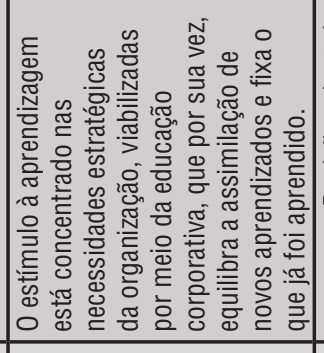 & 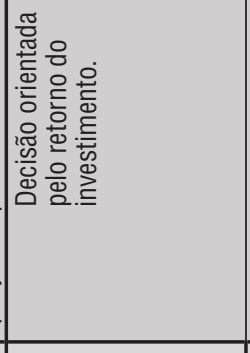 & 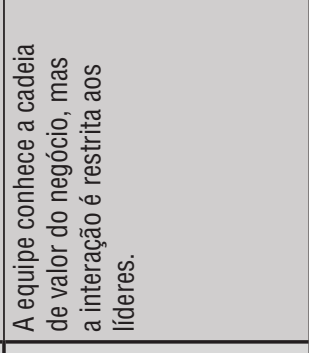 & 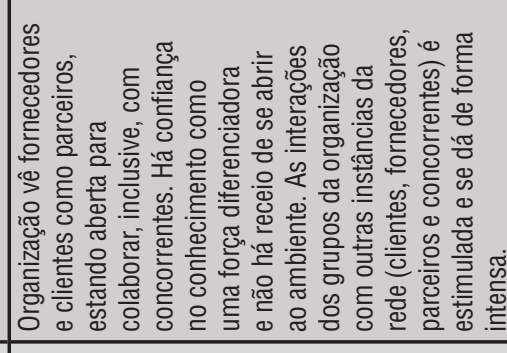 \\
\hline & \multirow{2}{*}{ 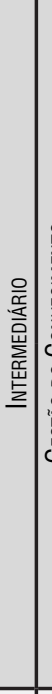 } & 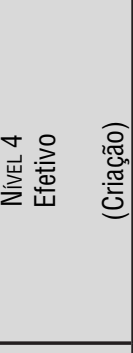 & 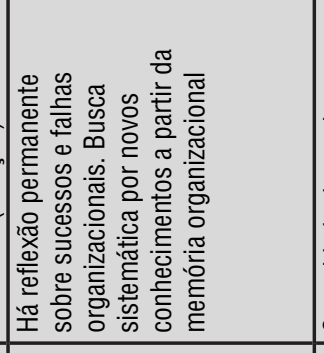 & 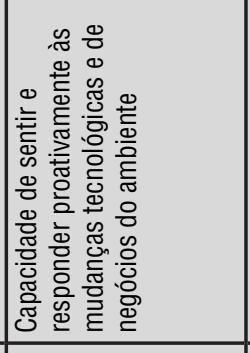 & 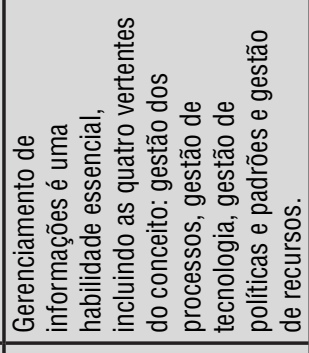 & 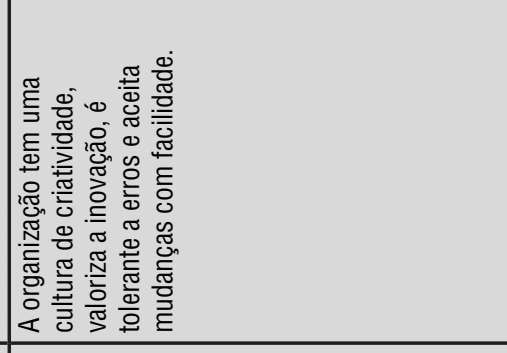 \\
\hline & & 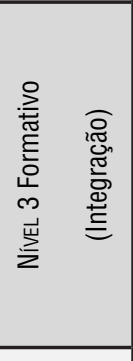 & 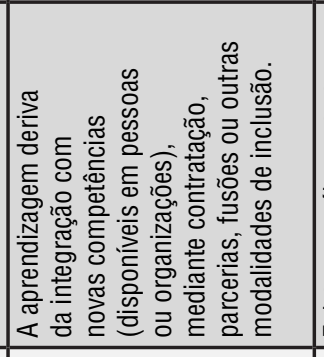 & 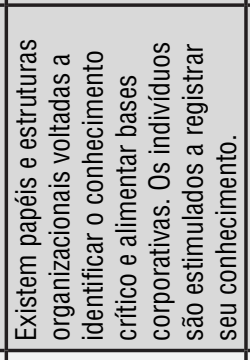 & 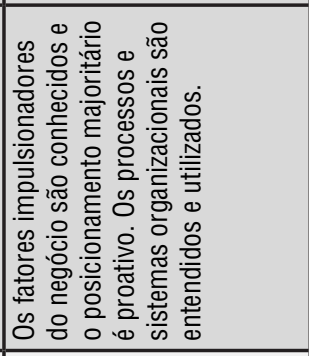 & 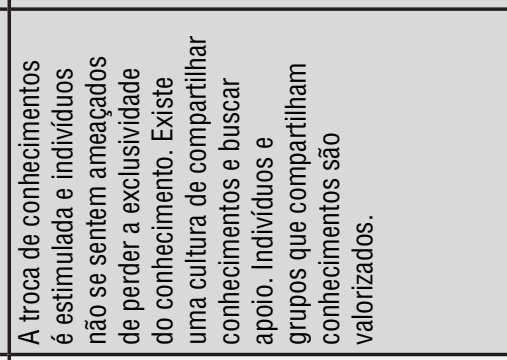 \\
\hline & \multirow{2}{*}{ 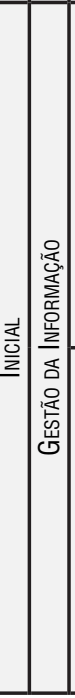 } & 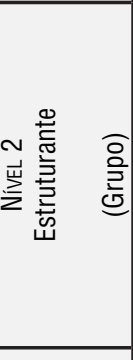 & 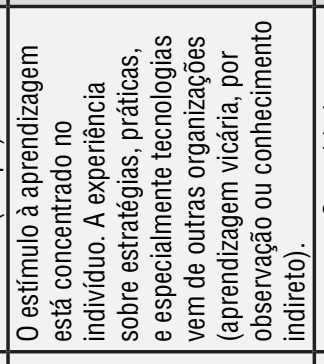 & 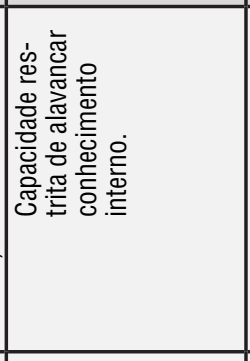 & 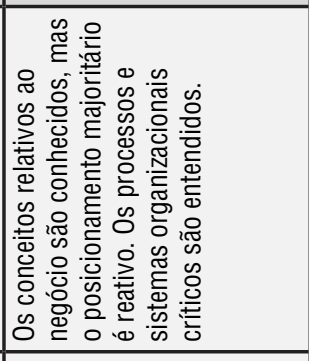 & 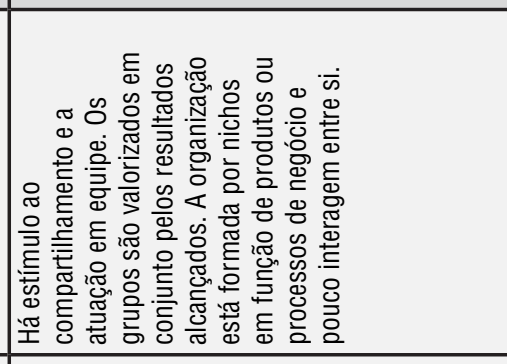 \\
\hline & & 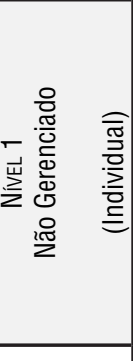 & 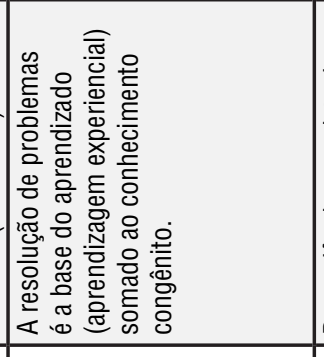 & 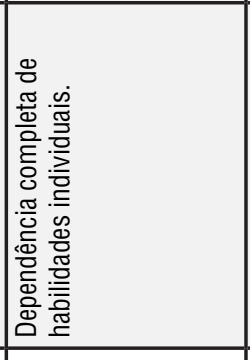 & 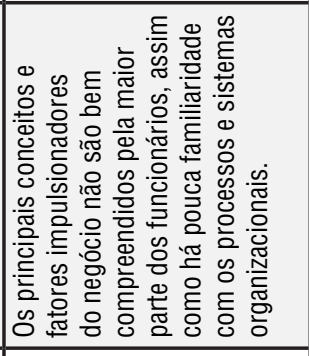 & 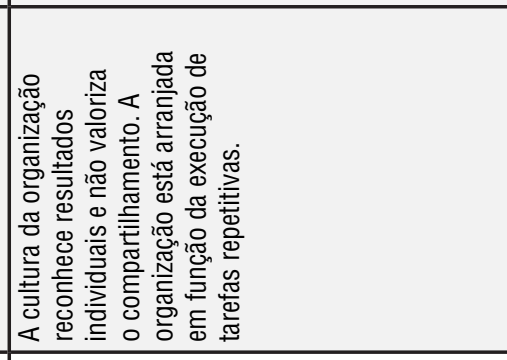 \\
\hline \multicolumn{3}{|c|}{ SHIY09تIHY } & 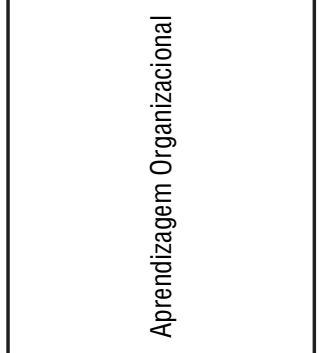 & 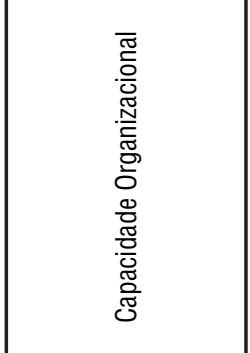 & 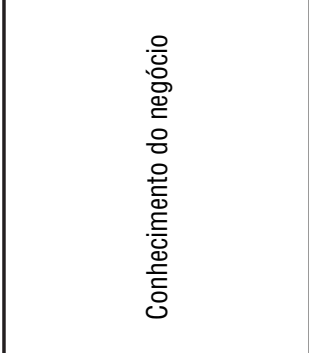 & 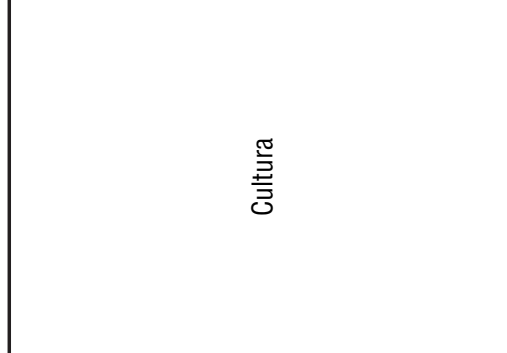 \\
\hline \multicolumn{3}{|c|}{ słosNawıI } & \multicolumn{4}{|c|}{ 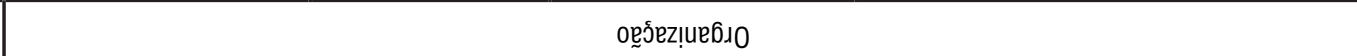 } \\
\hline
\end{tabular}




\begin{tabular}{|c|c|c|c|c|c|}
\hline 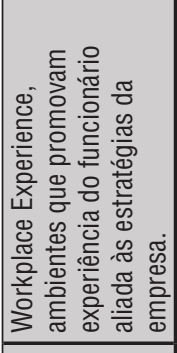 & 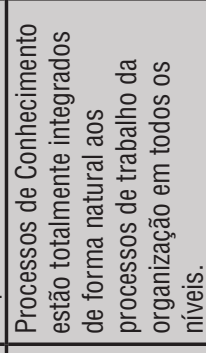 & 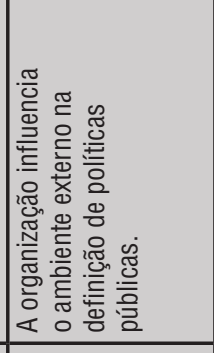 & 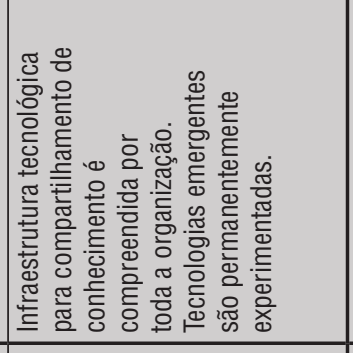 & 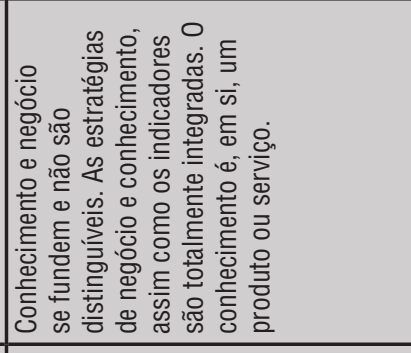 & 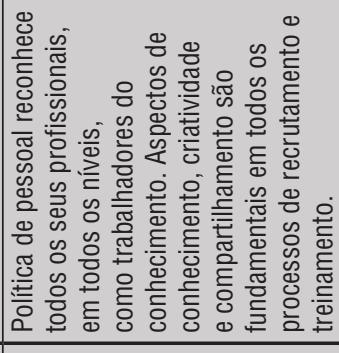 \\
\hline 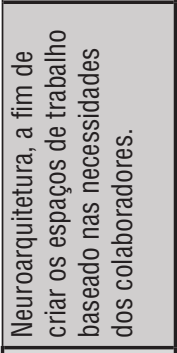 & 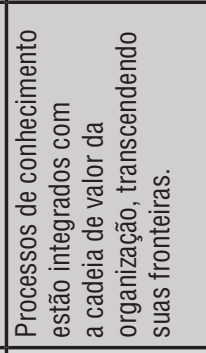 & 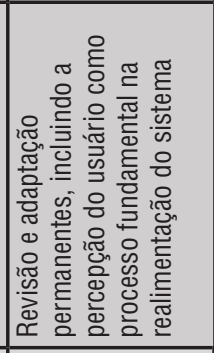 & 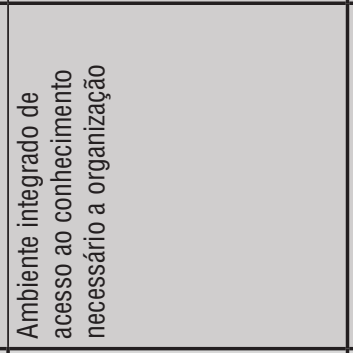 & 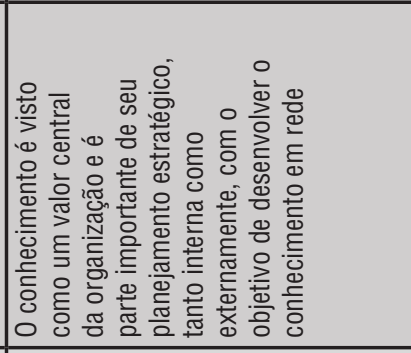 & 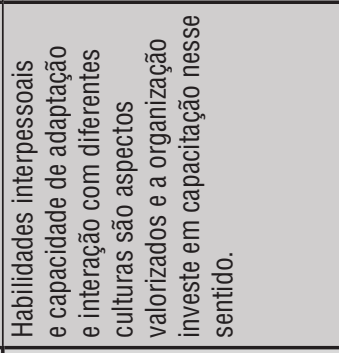 \\
\hline 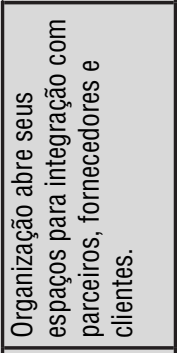 & 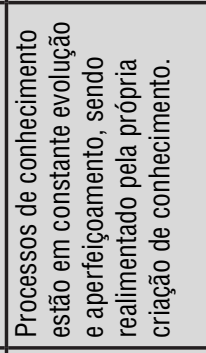 & 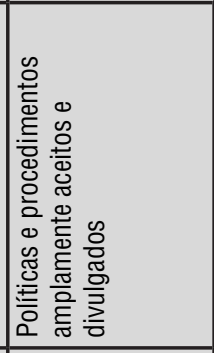 & 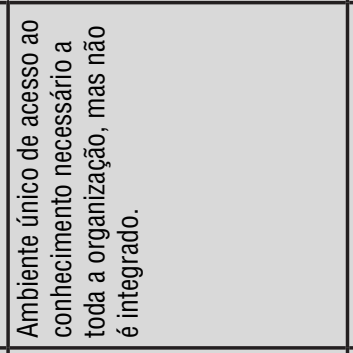 & 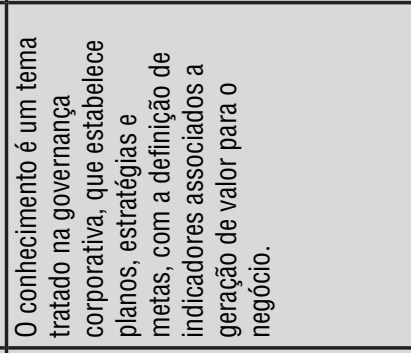 & 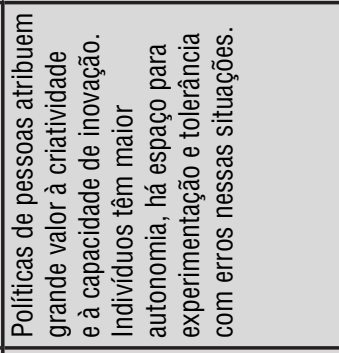 \\
\hline 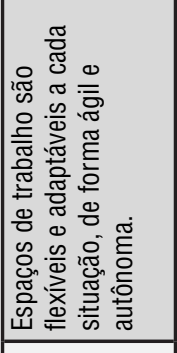 & 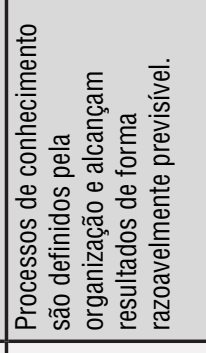 & 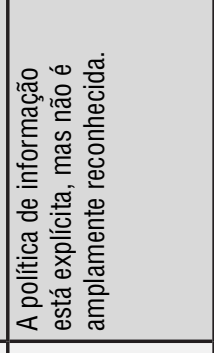 & 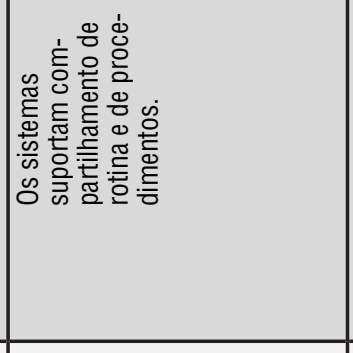 & 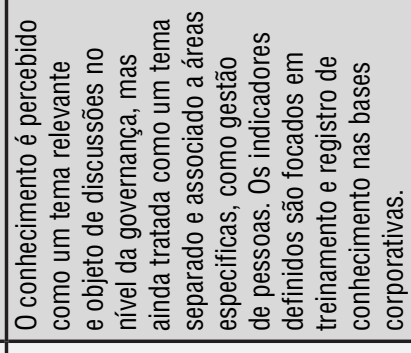 & 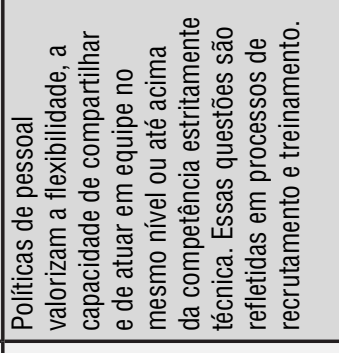 \\
\hline 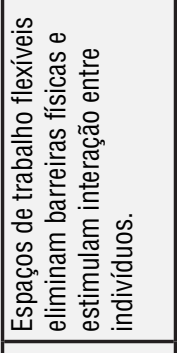 & 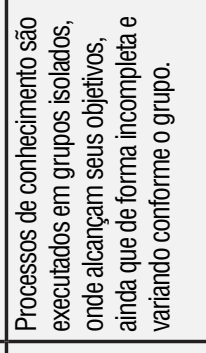 & 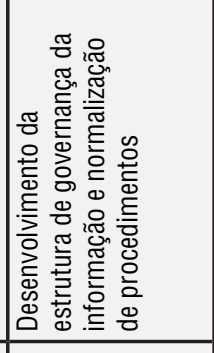 & 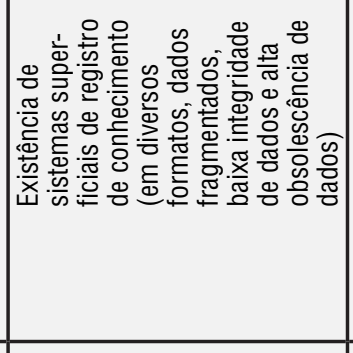 & 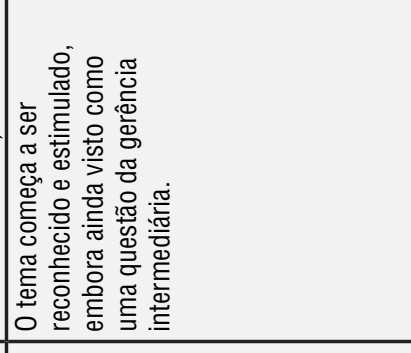 & 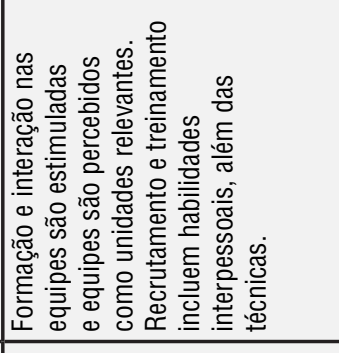 \\
\hline 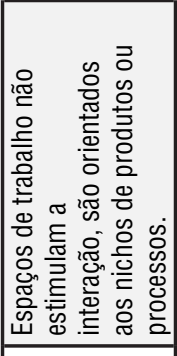 & 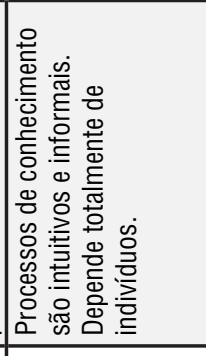 & 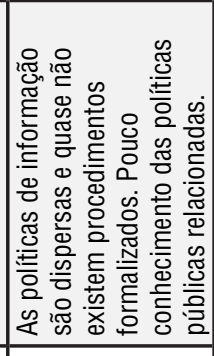 & 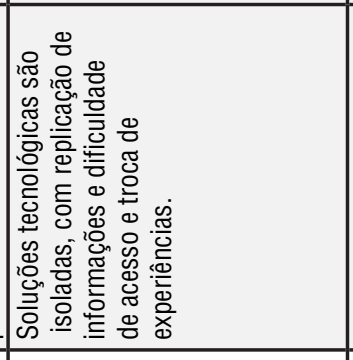 & 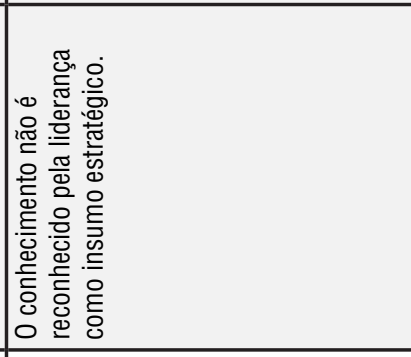 & 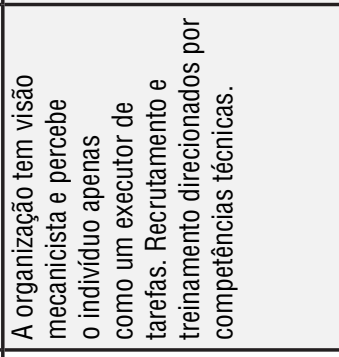 \\
\hline 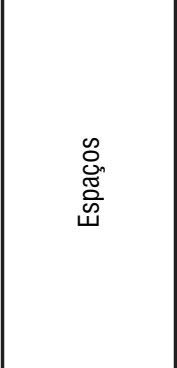 & 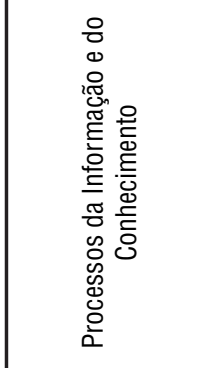 & 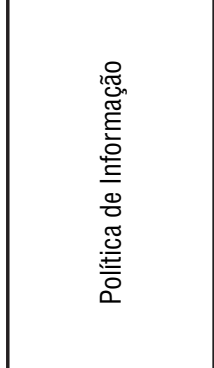 & 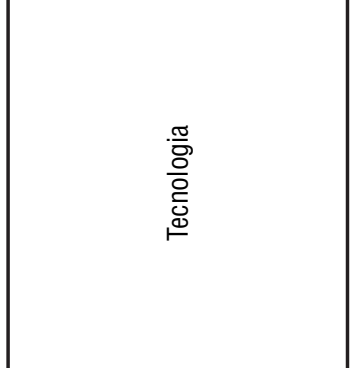 & 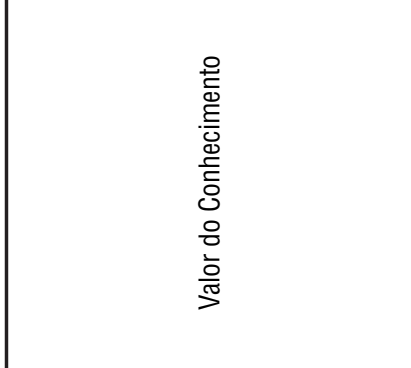 & 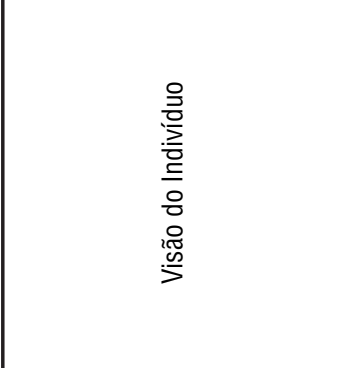 \\
\hline \multicolumn{6}{|c|}{ 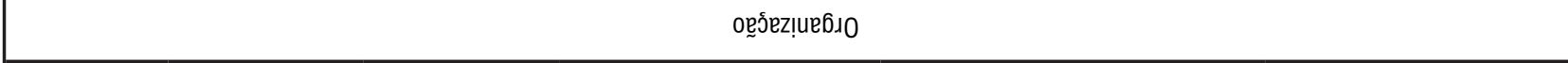 } \\
\hline
\end{tabular}


MODELO DE MATURIDADE EM INTELIGÊNCIA ORGANIZACIONAL:

uma visão integrada à gestão da informação, gestão do conhecimento e inteligência competitiva

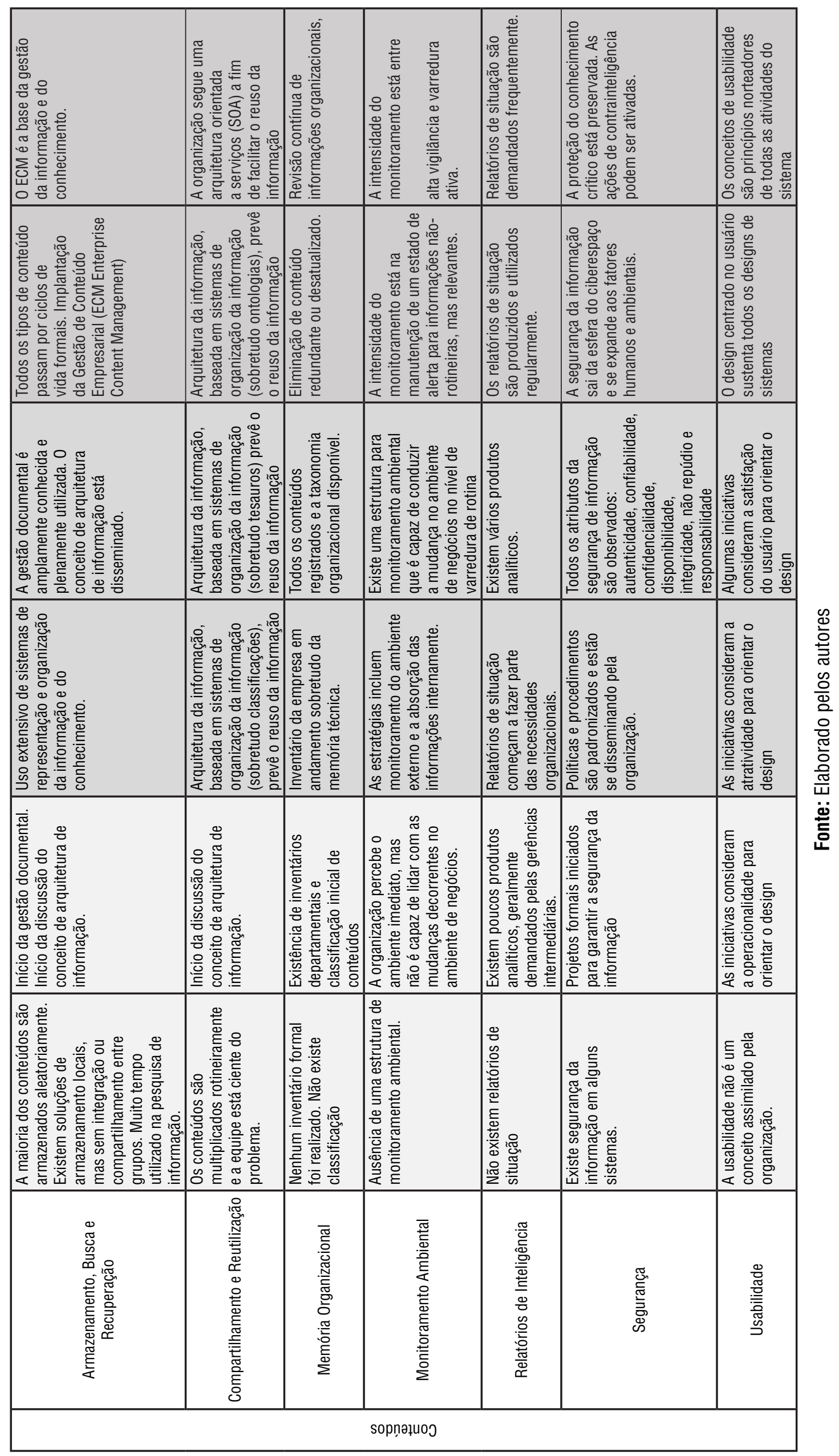




\section{CONSIDERAÇÕES FINAIS}

0 conceito de inteligência organizacional traz o reconhecimento do valor da informação organizacional, tanto proveniente do seu ambiente interno e quanto externo e os processos informacionais de agregação de valor e de tomada de decisão. 0 modelo de maturidade em inteligência organizacional, portanto, deve compreender o universo da informação estratégica organizacional.

Nesta perspectiva, a pesquisa propõe explicar o desenvolvimento da organização à luz da progressão em estágios de maturidade da informação e do conhecimento, numa abordagem que pode ser útil para compreensão, implantação, melhoria contínua, comparação ou autoavaliação de modelos de gestão da informação, gestão do conhecimento e inteligência competitiva.

0 modelo de maturidade em inteligência organizacional proposto, baseado em uma série de estágios lineares unidimensionais revelando que existe mais do que uma estreita relação entre gestão da informação, gestão de conhecimento e inteligência competitiva e que existe de fato uma dependência de maturidade entre estes elementos constituintes do modelo expandido de inteligência organizacional, que se inicia no estágio inicial da gestão da informação, que por sua vez é o fundamento para a gestão do conhecimento, que por sua vez é a sustentação e dá seguimento às ações de inteligência competitiva.

A pesquisa demonstrou, a partir dos estudos dos modelos de maturidade no campo da informação e do conhecimento, que gestão da informação fornece uma base estável para os esforços de gestão do conhecimento, uma vez que utiliza abordagens e práticas semelhantes e se vale das mesmas interfaces disciplinares para se desenvolver. E da mesma maneira, demonstrou que existe mais do que uma sinergia entre gestão do conhecimento e inteligência competitiva, que de fato, podese esperar da gestão do conhecimento ser um pré-requisito essencial à inteligência competitiva.

0 resultado da pesquisa propõe seis estágios de maturidade. No nível 1, chamado de não gerenciado, a principal característica de maturidade é estar associado ao indivíduo; e no nível 2, chamado estruturante, a principal característica de maturidade é estar associado aos grupos das unidades organizacionais. Esses dois níveis iniciais trazem majoritariamente as ações próprias da gestão da informação. No nível 3, chamado formativo, a principal característica de maturidade é estar associado à organização no nível de integração; e no nível 4, chamado de efetivo, a principal característica de maturidade é estar associado à competência de criação de conhecimento na organização. Esses dois níveis intermediários trazem majoritariamente as ações próprias da gestão do conhecimento. No nível 5 , chamado analítico, a principal característica de maturidade é estar em rede, e o último nível 6, chamado 
proativo, a principal característica de maturidade é lidar plenamente com a informação estratégica organizacional. Esses dois níveis avançados trazem majoritariamente as ações próprias da inteligência competitiva.

São 17 categorias distribuídas em duas dimensões, organizacional e de conteúdo. Na dimensão organizacional temos as categorias aprendizagem organizacional, capacidade organizacional, conhecimento do negócio, cultura, espaços, processos da informação e do conhecimento, política de informação, tecnologia, valor do conhecimento e visão do indivíduo. Na dimensão conteúdo temos as categorias armazenamento, busca e recuperação, compartilhamento e reutilização, memória organizacional, monitoramento ambiental, relatórios de inteligência, segurança e usabilidade.

À deriva dessa pesquisa, ficou claro a necessidade de aprofundar os estudos em modelos de maturidade em gestão documental, que em princípio parece parte do sustentáculo da inteligência organizacional.

\section{AGRADECIMENTOS}

Os autores agradecem às alunas Adriana Cristina da Silva e Maysa Barreto Ornelas Pereira da disciplina "Estudos Avançados em Ciência da Informação: Modelos de Maturidade em Gestão do Conhecimento" do Programa de Pós-graduação em Ciência da Informação da Universidade de Brasília pela participação nas discussões que deram origem a essa pesquisa.

\section{REFERÊNCIAS}

BARBOSA, R. R. Gestão da informação e do conhecimento: origens, polêmicas e perspectivas. Informação \& Informação, Londrina, v. 13, n. esp., p. 1-25, 2008.

CALOF, J. L.; WRIGHT, S. Competitive intelligence: a practitioner, academic and inter-disciplinary perspective. European Journal of marketing, v. 42, n. 7-8, p. 717-730, 2008.

CERVANTES, B. M. N.; RAIMUNDO, E. M.; COSTA, G. C. da ; MELLO, L. F. de; VALENTIM, M. L. P. Glossário trilíngue de termos em gestão da informação: subárea inteligência competitiva organizacional. Marília: Fundepe Editora; São Paulo: Cultura Acadêmica, 2010. 92p.

CHEN, X.H.; SNYMAN, M.M.M.; SEWDASS, N. Interrelationship between document management, information management and knowledge management. South African Journal of Information Management, v. 7, n. 3, 2005. 
CHOO, C. W. Information management for the intelligent organization: roles and implications for the information professions. In: DIGITAL LIBRARIES CONFERENCE. Proceedings [...]. Singapore: National Computer Board of Singapore, 1995.

CORRALL, S. Are we in the knowledge management business? Ariadne, v. 18, 1998.

CRUZ, Y. R; DOMÍNGUEZI, E. G. La inteligencia organizacional: necesario enfoque de gestión de información y del conocimiento. Ciência da Informação, Brasília, v.36, n.3, 2007.

DAVENPORT, T. H.; MARCHAND, D. Is KM just good information management. National Post Online, jul, 2001

GHANNAY, J. C.; MAMLOUK, Z. B. A. Synergy between competitive intelligence and knowledge management: a key for competitive advantage. Journal of Intelligence Studies in Business, v.2, p. 23-34, 2012.

HABER-VEJA, A.; MÁS-BASNUEVO, A. Inteligencia organizacional: conceptos, modelos y metodologías. Encontros Bibli: revista eletrônica de biblioteconomia e ciência da informação, v. 18, n. 38, p. 1-17, 2013.

HALL, C.; BENSOUSSAN, B. The Role of Competitive Intelligence in strategic management; results from an Australian survey. The Journal of Association for Global Strategic Information (AGSI), nov, p. 92-100, 1996.

HEPPES, D.; DU TOIT, A. Level of maturity of the competitive intelligence function: case study of a retail bank in South Africa. Aslib Proceedings: New Information Perspectives, v. 61, n. 1, p. 48-66, 2009.

ISO INTERNATIONAL ORGANIZATION FOR STANDARDIZATION. ISO 30.401: 2018 Knowledge management systems: requirements. Genebra, Suíça: ISO, 2018.

ITABORAHY, A. L. C.; MACHADO, R. P. M.; ALVARES, L. Modelo de maturidade em gestão do conhecimento: uma visão diacrônica. 2019. Trabalho de Conclusão de Disciplina do Programa de Pós-graduação em Ciência da Informação (Estudos Avançados em Ciência da Informação: Modelos de Maturidade em Gestão do Conhecimento) - Universidade de Brasília, Brasília, 2020.

KAHANER, L. Competitive intelligence: how to gather analyze and use information to move your business to the top. New York: Simon and Schuster, 1997.

MACHADO, R. P. M.; ITABORAHY, A. L. C.; ALVARES, L. Modelo de maturidade em gestão da informação: uma visão diacrônica. 2019. Trabalho de Conclusão de Disciplina do Programa de Pósgraduação em Ciência da Informação (Estudos Avançados em Ciência da Informação: Modelos de Maturidade em Gestão do Conhecimento) - Universidade de Brasília, Brasília, 2020.

MARCIAL, E. C. Aspectos fundamentais da inteligência competitiva e a ciência da informação. 2013. Tese (Doutorado em Ciência da Informação) - Faculdade de Ciência da Informação, Universidade de Brasília, Brasília, 2013. 
NÚÑEZ PAULA, I. Gestion del conocimiento: conceptos, aplicaciones y experiencias. In: SEMINARIO IBEROAMERICANO SOBRE TENDENCIAS MODERNAS EN GERENCIA DE LA CIENCIA Y LA INNOVACION TECNOLOGICA (IBERGECYT 2002). La Habana, 2002. [Anais....]. La Habana: Editorial Academia, 2002. p. 185.

OROZCO, S. E. Enfoque conceptual de la inteligencia organizacional en algunas fuentes de Información: aplicación en la industria biofarmacéutica. Ciencias de la Información, v. 29, n. 4, p.3545, 1998.

OUBRICH, M.; HAKMAOUI, A.; BIERWOLF, R.; HADDANI, M. Development of a competitive intelligence maturity model: insights from Moroccan companies. Journal of Intelligence Studies in Business, v. 8, n. 1, p. 25-36, 2018.

PETRIŞOR, I.; STRĂIN, N. A. Approaches on the competitive intelligence. The USV Annals of Economics and Public Administration, v. 13, n. 1, 2013

PONELIS, S.; FAIRER-WESSELS, F. A. Knowledge management: a literature overview. South African Journal of Library and Information Science, v. 66, n. 1, p. 1-9, 1998.

SCHLÖGL, C. Information and knowledge management: dimensions and approaches. Information Research, v.10, n.4, 2005.

SUTTON, M.J.D. Examination of the historical sensemaking processes representing the development of knowledge management programs in universities: case studies associated with an emergent discipline. 2007. Tese (Doutorado em Library and Information Studies) - Faculty of Education, McGill University, Montréal, Quebec, Canadá, 2007.

TARAPANOFF, K.; Marta VALENTIN, M. ; ALVARES, L. Trajetórias terminológicas relacionadas à inteligência competitiva. In: SEMINARIO HISPANO-BRASILEÑO DE INVESTIGACIÓN EN INFORMACIÓN, DOCUMENTACIÓN Y SOCIEDAD: PERSPECTIVAS Y TENDÊNCIAS, 5, 2016, Madrid, Espanha. Anais [...]. Madrid: Universidad Complutense de Madrid/ Facultad de Ciencias de la Documentación ; Brasília: Universidade de Brasília/Faculdade de Ciência da Informação, 2016. p.449467.

VAN DE HOVEN, J. Information Resource Management: Foundation for Knowledge Management. Information Systems Management, v. 18, n. 2, p. 80-83, 2006.

VAN DE VEN, A. H.; POOLE, M.S. Explaining development and change in organizations. The Academy of Management Review, v. 20, n. 3, p. 510-540, 1995.

WILENSKY, H.L. Organizational intelligence: knowledge and policy in government and industry. 2.ed. New York: Basic Books, 1967. 226p. 